\title{
Friedel-Crafts-type reaction of pyrene with diethyl 1-(isothiocyanato)alkylphosphonates. Efficient synthesis of highly fluorescent diethyl 1-(pyrene-1-carboxamido)alkylphosphonates and 1-(pyrene-1-carboxamido)methylphosphonic acid
}

\author{
Anna Wrona-Piotrowicz ${ }^{1}$, Janusz Zakrzewski ${ }^{* 1}$, Anna Gajda ${ }^{2}$, Tadeusz Gajda ${ }^{2}$, \\ Anna Makal ${ }^{3}$, Arnaud Brosseau ${ }^{4}$ and Rémi Métivier ${ }^{4}$
}

\section{Full Research Paper}

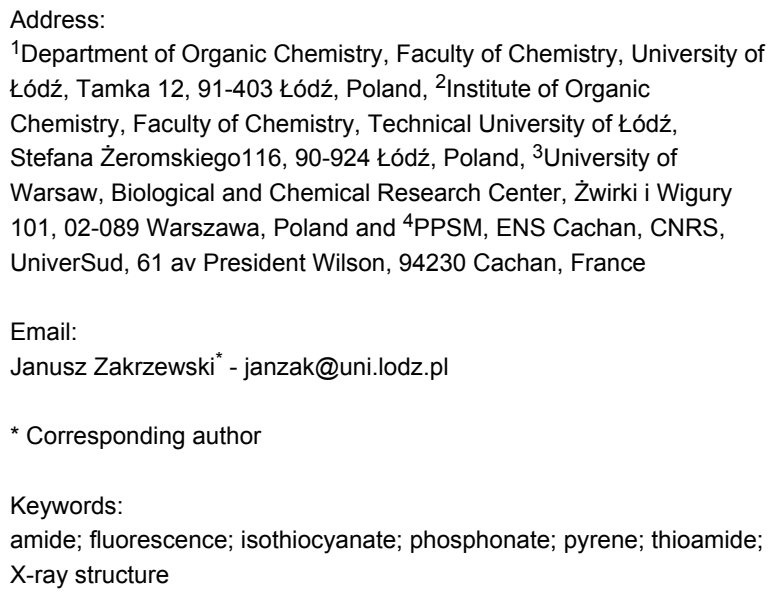

Beilstein J. Org. Chem. 2015, 11, 2451-2458.

doi:10.3762/bjoc.11.266

Received: 25 August 2015

Accepted: 18 November 2015

Published: 04 December 2015

Associate Editor: J. A. Murphy

(C) 2015 Wrona-Piotrowicz et al; licensee Beilstein-Institut.

License and terms: see end of document.

\footnotetext{
Abstract

Friedel-Crafts-type reaction of pyrene with diethyl 1-(isothiocyanato)alkylphosphonates promoted by trifluoromethanosulfonic acid afforded diethyl 1-(pyrene-1-carbothioamido)alkylphosphonates in 83-94\% yield. These compounds were transformed, in 87-94\% yield, into the corresponding diethyl 1-(pyrene-1-carboxamido)alkylphosphonates by treatment with Oxone ${ }^{\circledR}$. 1-(Pyrene-1-carboxamido)methylphosphonic acid was obtained in a $87 \%$ yield by treating the corresponding diethyl phosphonate with $\mathrm{Me}_{3} \mathrm{Si}-\mathrm{Br}$ in methanol. All of the synthesized amidophosphonates were emissive in solution and in the solid state. The presence of a phosphonato group brought about an approximately two-fold increase in solution fluorescence quantum yield in comparison with that of a model $N$-alkyl pyrene-1-carboxamide. This effect was tentatively explained by stiffening of the amidophosphonate lateral chain which was caused by the interaction (intramolecular hydrogen bond) of phosphonate and amide groups. The synthesized phosphonic acid was soluble in a biological aqueous buffer (PBS, $0.01 \mathrm{M}, \mathrm{pH} 7.35)$ and was strongly emissive under these conditions $\left(\lambda_{\mathrm{em}}=383,400 \mathrm{~nm}, \tau=18.7 \mathrm{~ns}, \Phi_{\mathrm{F}}>0.98\right)$. Solid-state emission of diethyl 1-(pyrene-1-carboxamido)methylphosphonate $\left(\lambda_{\max }=485 \mathrm{~nm} ; \Phi_{\mathrm{F}}=0.25\right.$ ) was assigned to $\pi-\pi$ aggregates, the presence of which was revealed by single-crystal X-ray diffraction analysis.
} 


\section{Introduction}

Friedel-Crafts-type reaction of arenes with isothiocyanates constitutes a useful method for the synthesis of aromatic secondary thioamides [1-6]. Our group [7] and others [8] have recently described an efficient modification of this method by using trifluoromethanesulfonic (triflic) acid as a promoter. Furthermore, we reported a simple procedure for the oxidative desulfurization of thioamides to amides via reaction with Oxone ${ }^{\circledR}$. Now we want to apply this approach to the synthesis of $N$-thioacyl- and acyl derivatives of 1-aminoalkylphosphonates from arenes and 1-(isothiocyanato)alkylphosphonates. 1-Aminoalkylphosphonates and their derivatives are compounds of biological relevance which have attracted the interest of biologically-oriented chemists and biochemists [9-12] Furthermore, the phosphonate group offers various possibilities of metal binding or anchoring to solid surfaces [13-20]. For our purposes we chose pyrene as a model arene because of its high reactivity in reaction with simple isothiocyanates [7], and because the expected products, 1-(pyrene-1-carbothioamido)alkylphosphonates, should be easily transformed into the corresponding fluorescent amides [7,21-28]. Herein we report the results of this study along with the photophysical properties of the synthesized 1-(pyrene-1-carboxamido)alkylphosphonates.

\section{Results and Discussion Syntheses}

The reactions performed in this work are shown in Scheme 1.

We found that pyrene reacts with isothiocyanates $\mathbf{1 a - d}$ in the presence of trifluoromethanesulfonic acid ( $\mathrm{TfOH})$ in dichloromethane at room temperature to afford 1-(pyrene-1-carbothioamido)alkylphosphonates $\mathbf{2 a - d}$ in high
(83-94\%) isolated yields. These yields are comparable with those obtained using simple alkyl isothiocyanates [7], which means that the phosphonato group is perfectly compatible with the reaction conditions. The structures of $\mathbf{2} \mathbf{a}-\mathbf{d}$ were confirmed by spectroscopic and elemental analysis data and (for 3a) by a single-crystal X-ray diffraction study (vide infra).

Thioamidophoshonates $\mathbf{2 a - d}$ readily reacted with Oxone ${ }^{\circledR}$ in acetonitrile-water at room temperature to afford the corresponding amidophosphonates $\mathbf{3 a - d}$ in $87-94 \%$ isolated yield (Scheme 1). Therefore, the indirect route to these compounds described above proved very efficient. We did not attempt to prepare 3a-d via direct Friedel-Crafts-type reaction of pyrene with (isocyanato)alkyl phosphonates because these compounds are difficult to synthesize and unstable [29]. Moreover, in our recent work we observed that reaction of pyrene with isothiocyanates proceeds more efficiently than an analogous reaction with isocyanates [7].

Additionally, compound 3a was transformed, using a standard procedure [30], to the corresponding phosphonic acid 4 isolated in $87 \%$ yield.

\section{Photophysical properties of $\mathbf{3 a}-\mathbf{d}$ and $\mathbf{4}$}

As expected, thioamides $\mathbf{2 a - d}$ were nonfluorescent (thioamide group is a well-known fluorescence quencher [31]). In contrast, the corresponding amides $\mathbf{3 a}-\mathbf{d}$ showed strong fluorescence emission in solution and in the solid state. We studied the photophysical properties of $\mathbf{3 a - d}$ and $\mathbf{4}$ and, for comparison, those of $\mathrm{N}$-alkylamide 5 (Figure 1).

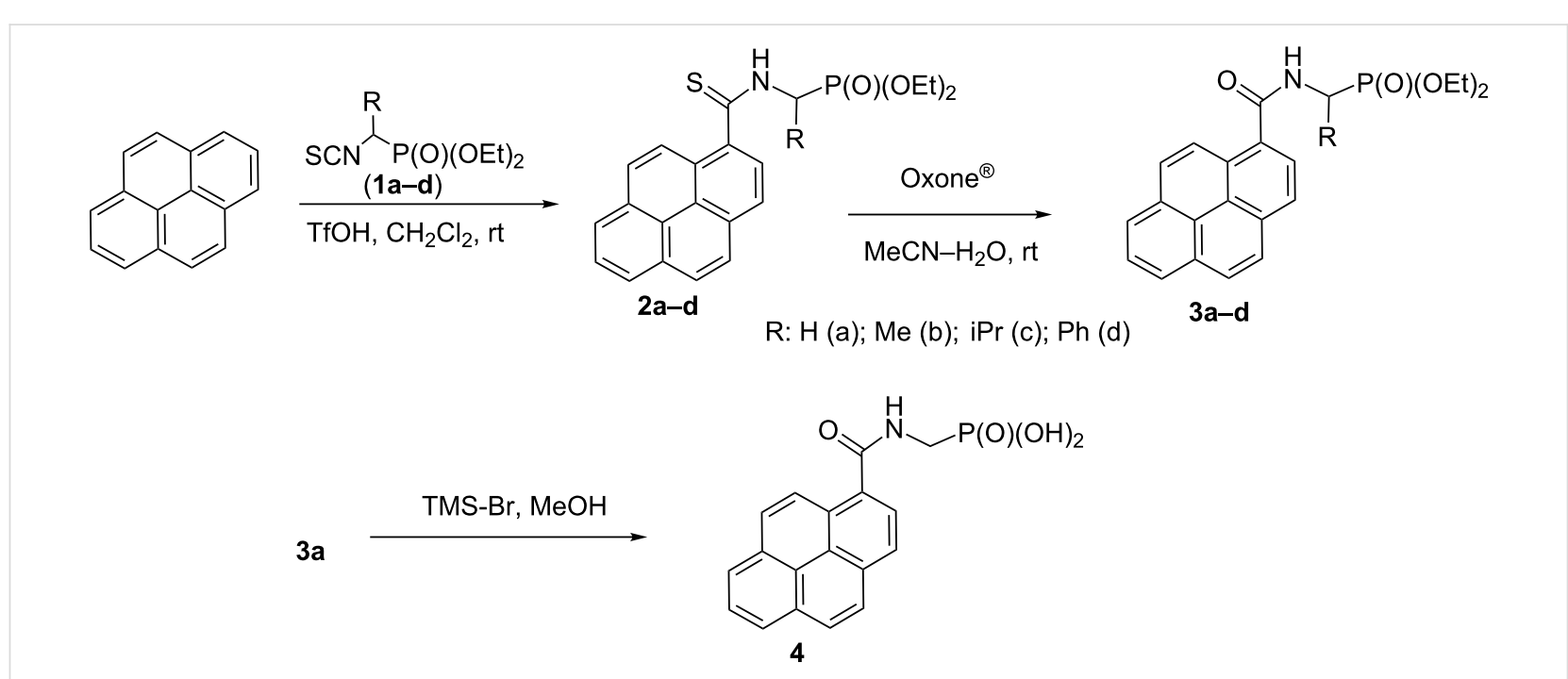


<smiles>CCCCNC(=O)c1ccc2ccc3cccc4ccc1c2c34</smiles>

Figure 1: Structure of amide 5.

The steady-state spectroscopic data for $\mathbf{3 a}-\mathbf{d}, \mathbf{4}$ and $\mathbf{5}$, along with fluorescence quantum yields in chloroform solutions, are presented in Table 1 (although it was recently reported that pyrene undergoes photodecomposition in this solvent [32], we found that this did not happen in the case of the compounds investigated here).

Electronic absorption and emission spectra of $\mathbf{3 a}$ in various solvents are shown in Figure 2.

The introduction of a phosphonato group into the $\mathrm{N}$-alkyl chain of the pyrene carboxamide fluorophore practically did not influ- ence the electronic absorption and emission spectra. Structured emission bands were observed showing only a small effect of solvent polarity (Figure 1). However, the fluorescence quantum yields of 3a-d and $\mathbf{4}$ were significantly higher than that of $\mathbf{5}$.

In order to explain this phenomenon we performed a timeresolved fluorescence study of $\mathbf{3 a}, \mathbf{4}$ and $\mathbf{5}$. The fluorescence decay curves are shown in Figure 3, whereas the fluorescence lifetimes and decay rate constants are presented in Table 2. All of the compounds under study displayed monoexponential decays, thus indicating one emitting species.

Table 2 shows that $\mathbf{3 a}$ displays a slightly shorter excited state lifetime (10.6 ns) than its alkyl analogue 5 (12.3 ns). The higher emission quantum yield of $\mathbf{3 a}$ results from $\mathrm{a} \approx 2.3$ times higher value of $k_{\mathrm{r}}$ and a concomitant ca. 1.8 times lower value of $k_{\mathrm{nr}}$. Notably, compound $\mathbf{4}$ displays a $k_{\mathrm{r}}$ value that is comparable to that of 3a $\left(k_{\mathrm{r}}=5.3-6.4 \times 10^{7} \mathrm{~s}^{-1}\right.$ for the two species), but its non-radiative deactivation pathway is almost entirely suppressed. Therefore, it may be concluded that the phosphonato group exerts a significant influence on the excited state deactivation kinetics of $\mathbf{3 a}$.

\begin{tabular}{|c|c|c|c|}
\hline Compound & Absorption $\lambda_{\max } / \mathrm{nm}\left(\varepsilon_{\max } / \mathrm{M}^{-1} \mathrm{~cm}^{-1}\right)$ & Emission ${ }^{\mathrm{b}} \lambda_{\max } / \mathrm{nm}$ & $\Phi_{\mathrm{F}}$ \\
\hline 3a & 331 (27450), 345 (50910), 380 (960) & 385,405 & 0.68 \\
\hline $3 \mathbf{b}$ & 332 (38710), 345 (52480), $379(4000)$ & 385,404 & 0.66 \\
\hline $3 c$ & 331 (37850), 345 (51610), 379 (2750) & 385,404 & 0.63 \\
\hline 3d & 331 (37220), 345 (51400), 379 (4200) & 387,406 & 0.68 \\
\hline $4^{a}$ & 327 (36350), 341 (50410), $376(5100)$ & 383,400 & $>0.98$ \\
\hline 5 & 316 (16990), 329 (37400), 345 (52360), 377 (2030) & 385,403 & 0.34 \\
\hline
\end{tabular}

${ }^{\mathrm{a}} 10^{-6} \mathrm{M}$ solution in $0.01 \mathrm{M}$ PBS $(\mathrm{pH} 7.35) .{ }^{\mathrm{b}} \lambda_{\text {excit }}=360 \mathrm{~nm}$.
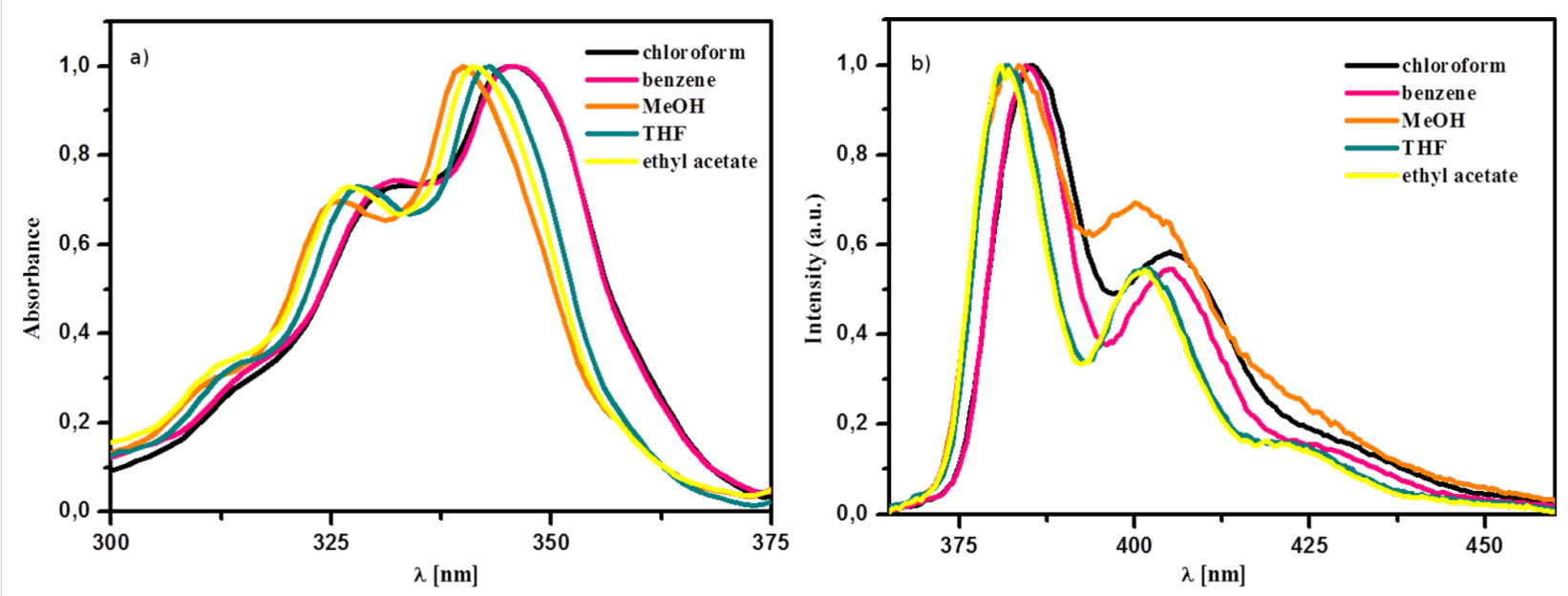

Figure 2: Normalized electronic absorption (a) and emission (b) spectra of $\mathbf{3 a}$ in various solvents. 

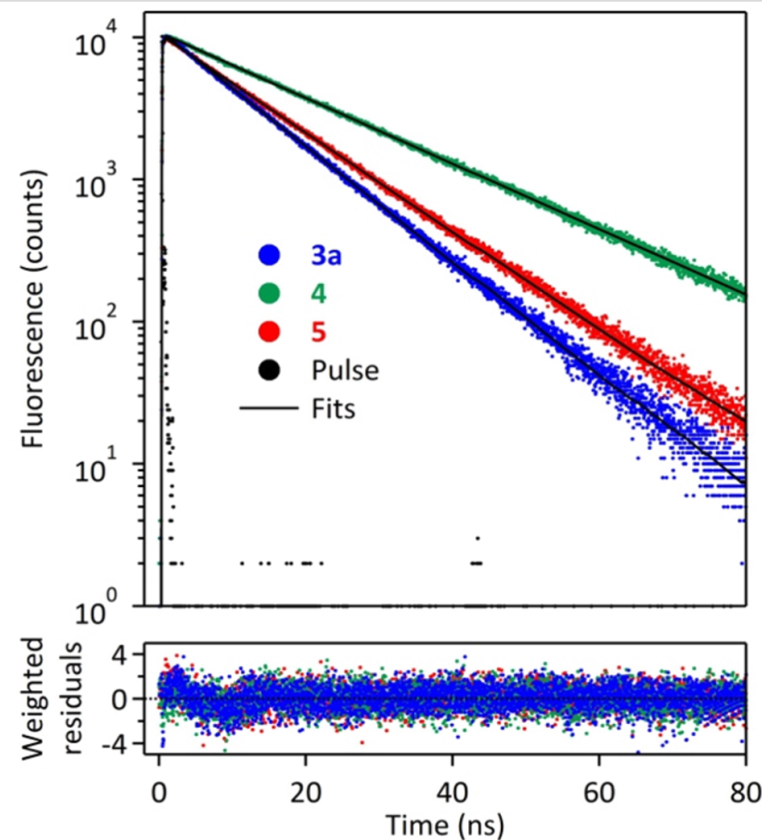

Figure 3: Fluorescence decay curves for $\mathbf{3 a}$ and $\mathbf{5}$ in chloroform and for 4 in 0.01 M PBS (pH 7.35). $\lambda_{\text {excit }}=360 \mathrm{~nm} ; \lambda_{\mathrm{em}}=385,390$ and $383 \mathrm{~nm}$, respectively.

Table 2: Fluorescence lifetimes and decay rate constants for $\mathbf{3 a}$ and $\mathbf{5}$
in $\mathrm{CHCl}_{3}$ and for $\mathbf{4}$ in $0.01 \mathrm{M}$ PBS $(\mathrm{pH} 7.35)$.
\begin{tabular}{cccc} 
Compound & $\begin{array}{c}\mathrm{T}(\mathrm{ns}) ; \\
\text { contribution }\end{array}$ & $k_{\mathrm{r}}^{\mathrm{a}} 10^{7} \mathrm{~s}^{-1}$ & $k_{\mathrm{nr}}^{\mathrm{b}} 10^{7} \mathrm{~s}^{-1}$ \\
\hline $\mathbf{3 a}$ & $10.6(1.00)$ & 6.4 & 3.0 \\
$\mathbf{4}$ & $18.7(1.00)$ & 5.2 & 0.1 \\
$\mathbf{5}$ & $12.3(1.00)$ & 2.8 & 5.4 \\
\hline
\end{tabular}

${ }^{\mathrm{a}} k_{\mathrm{r}}=\Phi_{\mathrm{F}} / \mathrm{T} ;{ }^{\mathrm{b}} k_{\mathrm{nr}}=\left(1-\Phi_{\mathrm{F}}\right) / \mathrm{T}$.

This influence may be attributed to the highly polar nature of the phosphonato group (electrostatic interaction between $\mathrm{C}=\mathrm{O}$ and $\mathrm{P}=\mathrm{O}$ dipoles may hamper rotations in the lateral chain responsible for non-radiative deactivation of the excited state) Another factor to be taken into consideration is the possibility of an intramolecular hydrogen bond between the $\mathrm{N}-\mathrm{H}$ and $\mathrm{P}=\mathrm{O}$ groups (Figure 4), which also leads to stiffening of the lateral chain and to blocking the non-radiative deactivation channel.<smiles>[R]C1N(C(=O)c2ccc3ccc4cccc5ccc2c3c45)CO[P+]1=O</smiles>

Figure 4: Intramolecular hydrogen bond in 3a-d.
The presence of such a bond was verified via variable concentration ${ }^{1} \mathrm{H}$ NMR spectroscopy [33], which showed only small variation $(\approx 0.2 \mathrm{ppm})$ in the chemical shift of the $\mathrm{N}-\mathrm{H}$ resonance of 3a across a concentration range of $0.1-0.005 \mathrm{M}$ in $\mathrm{CDCl}_{3}$ (see Supporting Information File 1).

Compound $\mathbf{4}$ was found to be insoluble in chloroform and in other weakly polar and nonpolar organic solvents but soluble in a biological buffer (0.01 M PBS, pH 7.35). Obviously, under these conditions it exists under an ionized form (anion or dianion). As was mentioned earlier, we observed efficient $\left(\Phi_{\mathrm{F}}>0.98\right)$ and relatively long-lived emission from 4 in the PBS buffer, which promises the possibility of its application in biological research.

Compound 3a was also emissive in the solid state $\left(\lambda_{\max }=485 \mathrm{~nm} ; \Phi_{\mathrm{F}}=0.25\right)$. The significant bathochromic shift $(80 \mathrm{~nm})$ and the broadness of the emission band in comparison with solution fluorescence (Figure 5) suggest the presence of emissive aggregates in the solid state. This was confirmed by an $\mathrm{X}$-ray diffraction study (vide infra).

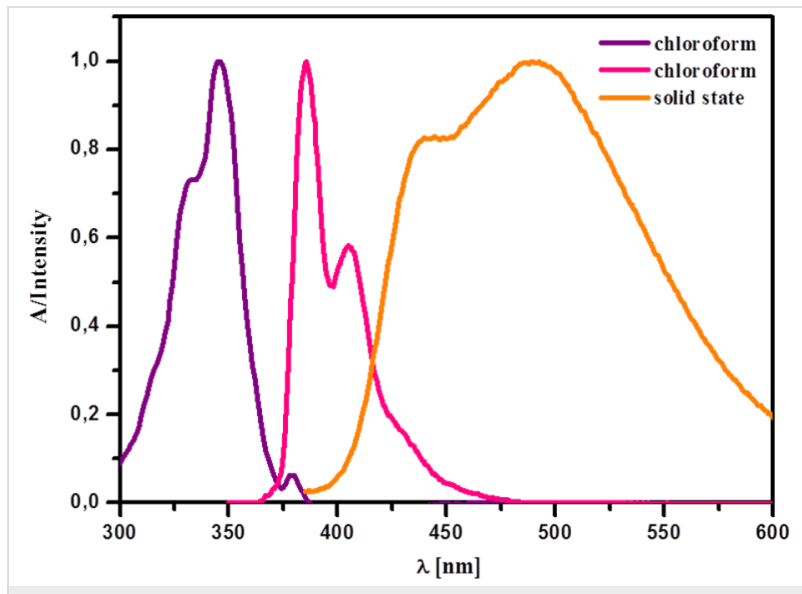

Figure 5: Normalized electronic absorption (violet) and emission (pink) spectrum of $3 \mathrm{a}$ in $\mathrm{CHCl}_{3}\left(c=10^{-6} \mathrm{M}\right)$ and its solid-state emission spectrum (yellow). $\lambda_{\text {excit }}=360 \mathrm{~nm}$.

\section{Molecular structure, crystal packing and solid-state fluorescence of $\mathbf{3 a}$}

Compound 3a crystallized from layered dichloromethane-hexane in the monoclinic space group $P 2{ }_{1} / c$, with a single molecule occupying an asymmetric unit in general position. Its molecular structure is shown in Figure 6.

The pyrenyl moiety in 3a is slightly bent, the angle between the planes of rings $\mathrm{C} 1-\mathrm{C} 2-\mathrm{C} 15-\mathrm{C} 14-\mathrm{C} 13-\mathrm{C} 12$ and $\mathrm{C} 5-\mathrm{C} 6-\mathrm{C} 7-\mathrm{C} 8-\mathrm{C} 9-\mathrm{C} 16$ is $4.23(13)^{\circ}$. The amide group is twisted by 57.1(2) degrees from the plane of the C1-C2-C15-C14-C13-C12 ring. Together with the C1-C17 
Figure 6: Molecular structure of 3a (ORTEP representation). Displacement ellipsoids were drawn at a $50 \%$ probability level. Hydrogen atom labels are analogous to those of bonded non- $\mathrm{H}$ atoms and were omitted for clarity, apart from the $\mathrm{H} 1$ atom which was involved in intermolecular hydrogen bond formation.

bond length exceeding $1.5 \AA$, this suggests that there is only very weak electronic conjugation between these units. The phosphonato group is also almost perpendicular to the plane of the amide group; the relevant $\mathrm{C} 17-\mathrm{N} 1-\mathrm{C} 18-\mathrm{P} 1$ torsion angle is $102.39(13)^{\circ}$. The most important geometrical parameters and intermolecular contacts for the structure are summarized in Table 3 and Table 4, respectively.

The molecules 3a form dimers in the crystal related by the crystallographic center of symmetry, bound by intermolecular $\mathrm{N} 1-\mathrm{H} 1 \cdots \mathrm{O} 3$ hydrogen bonds and stabilized by C19-H19B $\cdots \pi$ interactions. Similar $\mathrm{NH} \cdots \mathrm{O}=\mathrm{P}$ hydrogen-bonded dimers were already observed in the crystals of some aminophosphonates [34].

The dimers form strings along the crystallographic [001] direction, bound by relatively short $(\mathrm{H} \cdots \mathrm{O}$ distances of less than $2.75 \AA$ ) and intermolecular hydrogen $\mathrm{C}-\mathrm{H} \cdots \mathrm{O}$ bonds (Table 4). On the other hand, the pyrenyl moieties from the adjacent strings along [100] take part in $\pi \cdots \pi$ interactions, also forming molecular dimers (Figure 7). The shortest $\mathrm{C} \cdots \mathrm{C}$ distances are

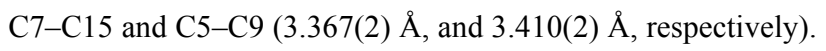

\begin{tabular}{ll} 
Table 3: Selected geometrical parameters for 3a. \\
Bond lengths & $\AA$ \\
\hline $\mathrm{P} 1-\mathrm{O} 2$ & $1.5761(11)$ \\
$\mathrm{P} 1-\mathrm{O} 3$ & $1.4751(10)$ \\
$\mathrm{P} 1-\mathrm{O} 4$ & $1.5694(11)$ \\
$\mathrm{P} 1-\mathrm{C} 18$ & $1.8000(14)$ \\
$\mathrm{C} 1-\mathrm{C} 17$ & $1.5053(18)$ \\
$\mathrm{O} 1-\mathrm{C} 17$ & $1.2315(16)$ \\
$\mathrm{N} 1-\mathrm{C} 18$ & $1.4500(17)$ \\
$\mathrm{N} 1-\mathrm{C} 17$ & $1.3463(17)$ \\
\hline Torsion angles & $\circ$ \\
\hline $\mathrm{C} 12-\mathrm{C} 15-\mathrm{C} 16-\mathrm{C} 5$ & $-179.43(12)$ \\
$\mathrm{C} 12-\mathrm{C} 15-\mathrm{C} 16-\mathrm{C} 9$ & $-0.42(19)$ \\
$\mathrm{C} 2-\mathrm{C} 1-\mathrm{C} 17-\mathrm{O} 1$ & $-123.81(15)$ \\
$\mathrm{C} 2-\mathrm{C} 1-\mathrm{C} 17-\mathrm{N} 1$ & $58.89(17)$ \\
$\mathrm{C} 17-\mathrm{N} 1-\mathrm{C} 18-\mathrm{P} 1$ & $102.39(13)$ \\
\end{tabular}

The presence of $\pi-\pi$-bonded aggregates in the crystal structure of $3 \mathbf{a}$ is in line with the observed features of solid-state emission of this compound (vide suppra).

\begin{tabular}{llllllll}
\hline \multicolumn{7}{l}{ Table 4: Selected hydrogen bonds in the crystal structure of $3 \mathbf{a}}$. \\
\hline $\mathrm{D}$ & $\mathrm{H}$ & $\mathrm{A}$ & $\mathrm{D}-\mathrm{H}[\AA]$ & $\mathrm{D}-\mathrm{H}[\AA]$ & $\mathrm{D}-\mathrm{H}[\AA]$ & $\mathrm{D}-\mathrm{H} \ldots \mathrm{A}\left[{ }^{\circ}\right]$ & Symmetry operation for $\mathrm{A}$ atom \\
\hline $\mathrm{N} 1$ & $\mathrm{H} 1$ & $\mathrm{O} 3$ & $0.871(14)$ & $1.941(14)$ & $2.7991(15)$ & $168.0(16)$ & $1-\mathrm{x},-\mathrm{y}, 1-\mathrm{z}$ \\
$\mathrm{C} 20$ & $\mathrm{H} 20 \mathrm{C}$ & $\mathrm{O} 1$ & 0.981 & 2.683 & $3.369(2)$ & 127.3 & $1-\mathrm{x},-1 / 2+\mathrm{y}, 1 / 2-\mathrm{z}$ \\
$\mathrm{C} 21$ & $\mathrm{H} 21 \mathrm{~A}$ & $\mathrm{O} 1$ & 0.990 & 2.6145 & $3.585(2)$ & 166.6 & $1-\mathrm{x},-1 / 2+\mathrm{y}, 1 / 2-\mathrm{z}$ \\
$\mathrm{C} 22$ & $\mathrm{H} 22 \mathrm{C}$ & $\mathrm{O} 3$ & 0.980 & 2.708 & $3.664(2)$ & 165.2 & $1-\mathrm{x}, 1 / 2+\mathrm{y}, 1 / 2-\mathrm{z}$ \\
\hline
\end{tabular}


a)
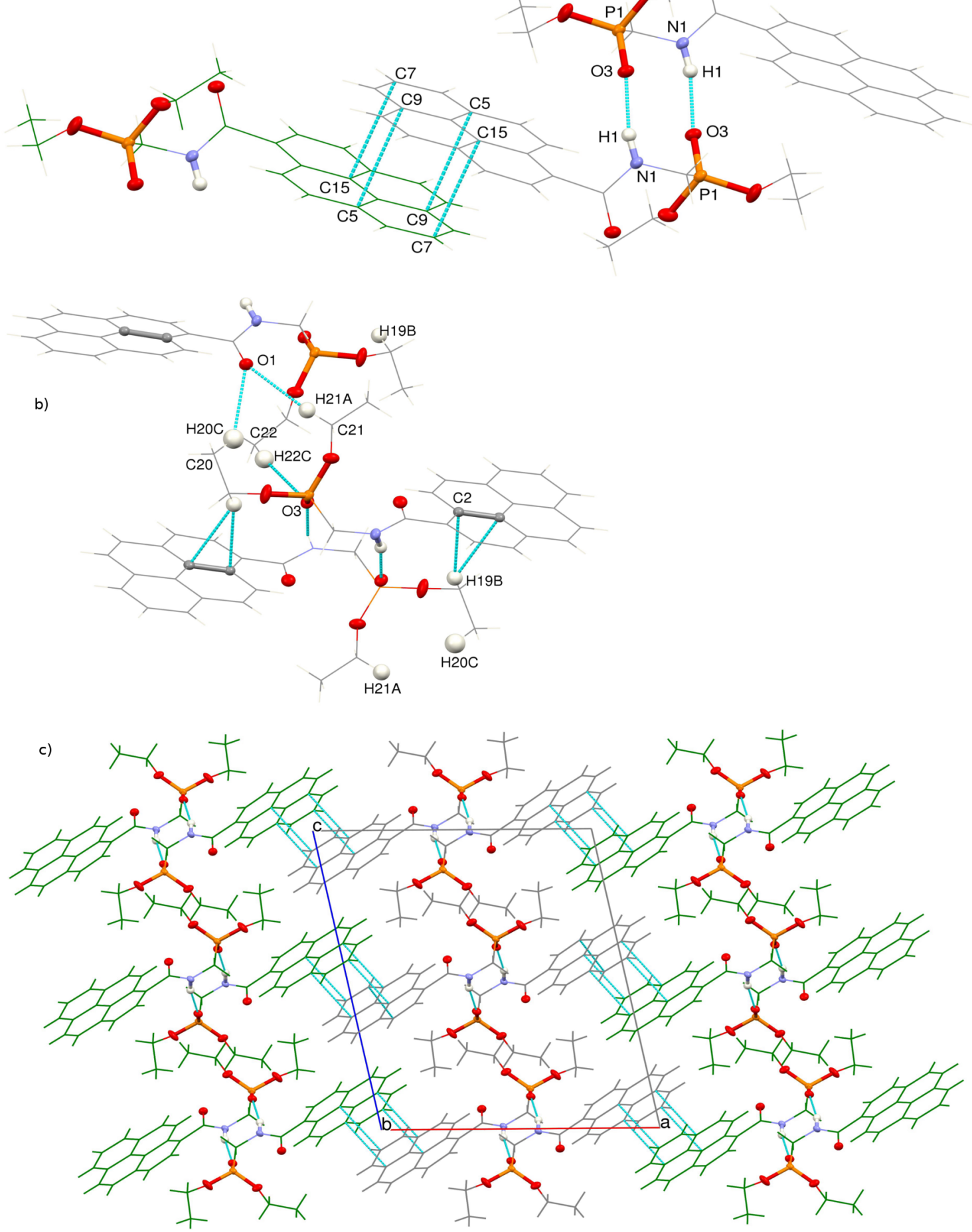

Figure 7: (a) Dimers of $\pi$-stacked and hydrogen-bonded molecules of 3a represented in single figures; (b) network of weak $\mathrm{C}-\mathrm{H} \cdots \mathrm{O}$ and $\mathrm{C}-\mathrm{H} \cdots \pi$ interactions stabilizing $\mathrm{H}$-bonded dimer strings and (c) crystal packing along the crystallographic $\mathrm{b}$ direction. Ellipsoids are drawn at $50 \%$ probability level for all non- $\mathrm{C}$ and non- $\mathrm{H}$ atoms. The remaining atoms are represented as wires in grey or green in order to differentiate between adjacent $\pi \cdots \Pi$ interacting chains of $\mathrm{H}$-bonded atoms. The shortest intermolecular contacts are represented in cyan. 


\section{Conclusion}

We demonstrated the feasibility of the Friedel-Crafts reaction with 1-(isothiocyanato)alkylphosphonates by using pyrene as an arene. The pyrenyl thioamidoalkylphosphonates formed in this reaction can be readily transformed into the corresponding fluorescent amidoalkylphosphonates. It is worthy to note that this class of compounds offers numerous possibilities of chemical transformations $[35,36]$. The pyrenyl amidoalkylphosphonates emit fluorescence with quantum yields ca. 2 times higher than simple $N$-substituted pyrene-1-carboxamides. Solid-state emission assigned to the aggregates was also observed. Finally, a pyrenecarboxamide phosphonic acid was synthesized, showing very efficient emission in a biological buffer and promising possible biological applications.

\section{Supporting Information}

\section{Supporting Information File 1}

Experimental procedures, characterization of new compounds, and details of the photophysical study. [http://www.beilstein-journals.org/bjoc/content/ supplementary/1860-5397-11-266-S1.pdf]

\section{Supporting Information File 2}

CIF file of compound $\mathbf{3 a}$.

[http://www.beilstein-journals.org/bjoc/content/ supplementary/1860-5397-11-266-S2.cif]

\section{Acknowledgements}

Financial support from the National Science Centre Poland (NCN, Grant Harmonia UMO-2012/04/M/ST5/00712) is gratefully acknowledged.

\section{References}

1. Arnswald, M.; Neumann, W. P. J. Org. Chem. 1993, 58, 7022-7028. doi:10.1021/jo00077a020

2. Jagodziński, T. Org. Prep. Proced. Int. 1990, 22, 755-760. doi:10.1080/00304949009457904

3. Papadopoulos, E. P. J. Org. Chem. 1976, 41, 962-965. doi:10.1021/jo00868a013

4. Plażuk, D.; Zakrzewski, J.; Rybarczyk-Pirek, A.; Domagala, S. J. Organomet. Chem. 2005, 690, 4302-4308. doi:10.1016/j.jorganchem.2005.06.037

5. Tabak, G.; Pham, T.-N.; Levesque, G.; Haraoubia, R. J. Polym. Sci., Part A: Polym. Chem. 1998, 36, 117-127. doi:10.1002/(sici)1099-0518(19980115)36:1<117::aid-pola16>3.0.co;2$\mathrm{m}$

6. Wesołowska, A.; Gros, L.; Westerlich, S.; Jagodziński, T. S. ARKIVOC 2008, No. xv, 239-255.

7. Wrona-Piotrowicz, A.; Zakrzewski, J.; Métivier, R.; Brosseau, A.; Makal, A.; Woźniak, K. RSC Adv. 2014, 4, 56003-56012. doi:10.1039/C4RA07045C
8. Varun, B. V.; Sood, A.; Prabhu, K. R. RSC Adv. 2014, 4, 60798-60807. doi:10.1039/C4RA12944J

9. Berlicki, L.; Kafarski, P. Curr. Org. Chem. 2005, 9, 1829-1850. doi:10.2174/138527205774913088

10. Grembecka, J.; Kafarski, P. Mini-Rev. Med. Chem. 2001, 1, 133-144. doi:10.2174/1389557013406990

11. Kafarski, P.; Lejczak, B. Phosphorus, Sulfur Silicon Relat. Elem. 1991, 63, 193-215. doi:10.1080/10426509108029443

12. Kafarski, P.; Lejczak, B. Curr. Med. Chem. - Anti-Cancer Agents 2001, 1, 301-312. doi:10.2174/1568011013354543

13. Goura, J.; Chandrasekhar, V. Chem. Rev. 2015, 115, 6854-6965. doi:10.1021/acs.chemrev.5b00107

14. Clearfield, A. Curr. Opin. Solid State Mater. Sci. 2002, 6, 495-506. doi:10.1016/s1359-0286(02)00151-1

15. Clearfield, A.; Sharma, C. V. K.; Zhang, B. P. Chem. Mater. 2001, 13, 3099-3112. doi:10.1021/cm010164u

16. Gałęzowska, J.; Gumienna-Kontecka, E. Coord. Chem. Rev. 2012, 256, 105-124. doi:10.1016/j.ccr.2011.07.002

17. Katz, H. E. Chem. Mater. 1994, 6, 2227-2232. doi:10.1021/cm00048a009

18. Mao, J.-G. Coord. Chem. Rev. 2007, 251, 1493-1520. doi:10.1016/j.ccr.2007.02.008

19. Shimizu, G. K. H.; Vaidhyanathan, R.; Taylor, J. M. Chem. Soc. Rev. 2009, 38, 1430-1449. doi:10.1039/b802423p

20. Tušek-Božić, L. Curr. Med. Chem. 2013, 20, 2096-2117. doi:10.2174/0929867311320160004

21. Niko, Y.; Cho, Y.; Kawauchi, S.; Konishi, G.-i. RSC Adv. 2014, 4, 36480-36484. doi:10.1039/C4RA06282E

22. Niko, Y.; Konishi, G.-i. Macromolecules 2012, 45, 2327-2337. doi:10.1021/ma3001252

23. Niko, Y.; Hiroshige, Y.; Kawauchi, S.; Konishi, G.-i. J. Org. Chem. 2012, 77, 3986-3996. doi:10.1021/jo300317r

24. Niko, Y.; Hiroshige, Y.; Kawauchi, S.; Konishi, G.-i. Tetrahedron 2012, 68, 6177-6185. doi:10.1016/j.tet.2012.05.072

25. Hwang, J.; Choi, M. G.; Eor, S.; Chang, S.-K. Inorg. Chem. 2012, 51, 1634-1639. doi:10.1021/ic2019428

26. Kerr, C. E.; Mitchell, C. D.; Ying, Y.-M.; Eaton, B. E.; Netzel, T. L. J. Phys. Chem. B 2000, 104, 2166-2175. doi:10.1021/jp993776z

27. Kerr, C. E.; Mitchell, C. D.; Headrick, J.; Eaton, B. E.; Netzel, T. L. J. Phys. Chem. B 2000, 104, 1637-1650. doi:10.1021/jp992773j

28. Frazer, J. D.; Horner, S. M.; Woski, S. A. Tetrahedron Lett. 1998, 39, 1279-1282. doi:10.1016/S0040-4039(97)10853-X

29. Coutrot, P.; Grison, C.; Charbonnier-Gérardin, C. Tetrahedron 1992, 48, 9841-9868. doi:10.1016/S0040-4020(01)92278-1

30. McKenna, C. E.; Higa, M. T.; Cheung, N. H.; McKenna, M.-C. Tetrahedron Lett. 1977, 18, 155-158. doi:10.1016/S0040-4039(01)92575-4

31. Goldberg, J. M.; Wissner, R. F.; Klein, A. M.; Petersson, E. J. Chem. Commun. 2012, 48, 1550-1552. doi:10.1039/c1cc14708k

32. Aguilera-Sigalat, J.; Sanchez-SanMartín, J.; Agudelo-Morales, C. E.; Zaballos, E.; Galian, R. E.; Pérez-Prieto, J. ChemPhysChem 2012, 13, 835-844. doi:10.1002/cphc.201100843

33. Smith, A. B., III; Ducry, L.; Corbett, R. M.; Hirschmann, R. Org. Lett. 2000, 2, 3887-3890. doi:10.1021/ol0066330

34. Juribašić, M.; Bellotto, L.; Tušek-Božić, L. Struct. Chem. 2012, 23 , 257-266. doi:10.1007/s11224-011-9859-z

35. Katritzky, A. R.; Zhang, G.; Jiang, J. J. Org. Chem. 1994, 59 , 4556-4560. doi:10.1021/jo00095a035 
36. Kuźnik, A.; Mazurkiewicz, R.; Grymel, M.; Zielińska, K.; Adamek, J.;

Chmielewska, E.; Bochno, M.; Kubica, S. Beilstein J. Org. Chem. 2015,

11, 1418-1424. doi:10.3762/bjoc.11.153

\section{License and Terms}

This is an Open Access article under the terms of the Creative Commons Attribution License

(http://creativecommons.org/licenses/by/2.0), which permits unrestricted use, distribution, and reproduction in any medium, provided the original work is properly cited.

The license is subject to the Beilstein Journal of Organic Chemistry terms and conditions:

(http://www.beilstein-journals.org/bjoc)

The definitive version of this article is the electronic one which can be found at:

doi:10.3762/bjoc. 11.266 